Available online at http://jddtonline.info

RESEARCHARTICLE

\title{
DESIGN AND CHARECTERIZATION OF NOVEL TRANSDERMAL THERAPEUTIC SYSTEMS OF FELODIPINE
}

\author{
Jiji Jose*1, Narayanacharyulu $\mathbf{R}^{2}$, Molly Mathew ${ }^{1}$ \\ ${ }^{1}$ Dept. of Pharmaceutics, Malik Deenar College of Pharmacy, Kasaragod, Kerala-671321, India \\ ${ }^{2}$ Dept. of Pharmaceutics, NGSM Institute of Pharmaceutical Sciences, Mangalore, Karnataka-India \\ *Corresponding Author's E-mail: jijimpharm@yahoo.co.in, Mob: +919995987152
}

Received 13 Sep 2012; Review Completed 13 Oct 2012; Accepted 17 Oct 2012, Available online 15 Nov 2012

\begin{abstract}
Felodipine is an effective calcium channel blocker, mainly used in the treatment of hypertension and angina pectoris. To overcome the low oral bioavailability of felodipine, the present work was designed to develop transdermal therapeutic system for felodipine using the polymer blend of eudragit RL 100 (ERL) / RS 100 (ERS) by solvent casting method and to study the effect of polymer composition, plasticizer and permeation enhancer on the physico-mechanical and in-vitro drug release characteristics of the film. Dibutyl phthalate (DBP) and oleic acid (OA) were used as plasticizer and permeation enhancer respectively. Different formulations with varied concentration of polymers, plasticizers and permeation enhancers were done and optimization of the concentration of formulation components was performed. Incorporation of DBP improved the flexibility, folding endurance and handling properties of the films. There was no significant difference in the drug content among patches indicating the uniformity in drug content. Increasing the concentration of ERL, and the presence of plasticizer were found to increase the in vitro drug release of the films. The patches were also evaluated for ex vivo skin permeation using human cadaver skin. The presence of OA produced significant increase in the flux and permeability constant. The formulation with ERL: ERS ratio $4: 1,5 \% \mathrm{w} / \mathrm{w}$ OA as permeation enhancer and $20 \% \mathrm{w} / \mathrm{w}$ DBP as plasticizer showed the best results which exhibited the cumulative percentage of drug release of $75.73 \pm 2.179 \%$ and the cumulative amount of drug permeation across skin of $4321 \pm 11.533$ $\mu \mathrm{g} / \mathrm{cm}^{2}$ in $24 \mathrm{hrs}$. Drug-excipient interaction studies were carried out using DSC and IR technique; films indicated no chemical interaction between drug and excipient. The results of the skin irritation studies showed no noticeable irritancy on rabbit skin indicating the skin compatibility of the drug as well as polymer. An attempt was made to develop the complete transdermal system of the drug by using backing membrane and release liner.

Key-words: Transdermal Therapeutic System, Felodipine, Eudragit, Dibutyl Phthalate, Skin Permeation.
\end{abstract}

\section{INTRODUCTION}

In the recent years, considerable attention has been focused on the development of new drug delivery systems. The therapeutic efficacy and safety of the drugs administered by conventional methods can be improved by more precise spatial and temporal placement within the body, thereby reducing both the size and number of doses through a controlled drug delivery. Among the wide variety of novel controlled drug delivery systems, the transdermal delivery of drugs for the systemic treatment of diseases has acquired increasing interest in recent years due to its potential in avoiding the hepatic first pass effect, thus achieving high systemic bioavailability of drugs and capable of sustaining the drug release for prolonged period of time. Moreover, it provides suitability for self-administration and rapid termination of drug effect if needed, leading to better patient acceptance and compliance $e^{1,2}$.

Transdermal therapeutic systems are ideally suited for diseases that demand chronic treatment. Cardiac disorders such as hypertension, angina pectoris and congestive cardiac failure are the diseases equally prevalent in the developed and the undeveloped countries, demands chronic treatment. Cardiac patients need to be on prolonged medication, and some times life long therapy is advised. Transdermal delivery is considered to be the ideal method for cardiac drugs which can bypass the difficulties of firstpass metabolism, enable absolute elimination of GIT toxic effects, maintain the steady plasma level of drug for a prolonged period and deliver the drug at predetermined rate. Hence, for last two decades, it remained an area of vital research of interest and industries alike to take up challenging projects in this particular arena ${ }^{3}$.

Felodipine (FD), a potent calcium channel blocker which is widely used in the treatment of hypertension and angina pectoris. Although it is rapidly and almost completely absorbed from the GIT, it undergoes extensive first pass metabolism resulting in a bioavailability of about $15 \%$ after its oral administration. Hence to achieve therapeutic concentration, frequent dosing or large doses are required. Large doses can produce bradycardia, hypotension and other adverse effects $^{4,5}$. Hence to improve the bioavailability, therapeutic efficacy, patient compliance and to reduce the frequency of dosing and its side effects, transdermal drug delivery systems are better suitable for FD.

\section{MATERIALS AND METHODS}

\section{Materials}

Felodipine was obtained as gift sample from Cipla Ltd. Mumbai. Eudragit RS 100 (ERS) and Eudragit RL 100 (ERL) were procured from Degussa India Pvt. Ltd, Mumbai. Oleic acid (OA), dibutyl phthalate (DBP), 
methanol and acetone were of analytical grade purchased from Sree Durga Chemicals, Mangalore. Cellophane membrane was obtained from Sigma Chemicals Co., St. Louis, USA.
The patches were prepared by casting method. A flat square shaped, aluminium foil coated glass molds having surface area $25 \mathrm{~cm}^{2}$ were fabricated for casting the patches.

\section{Formulation of transdermal patches}

Table 1: Composition of formulations

\begin{tabular}{|c|c|c|c|c|c|c|c|}
\hline $\begin{array}{c}\text { Formulation } \\
\text { Code }\end{array}$ & $\begin{array}{c}\text { Polymer } \\
\text { ratio } \\
\text { ERL/ERS }\end{array}$ & ERL (mg) & $\begin{array}{c}\text { ERS } \\
(\mathbf{m g})\end{array}$ & FD (mg) & $\begin{array}{c}\text { DBP } \\
(\mathbf{m g})\end{array}$ & OA (mg) & $\begin{array}{c}\text { Acetone } \\
\text { up to (m) }\end{array}$ \\
\hline F1 & $1: 4$ & 140 & 560 & 210 & - & - & 7 \\
\hline F2 & $2: 3$ & 280 & 420 & 210 & - & - & 7 \\
\hline F3 & $3: 2$ & 420 & 280 & 210 & - & - & 7 \\
\hline F4 & $4: 1$ & 560 & 140 & 210 & - & - & 7 \\
\hline F5 & $4: 1$ & 560 & 140 & 210 & 70 & & 7 \\
\hline F6 & $4: 1$ & 560 & 140 & 210 & 140 & & 7 \\
\hline F7 & $4: 1$ & 560 & 140 & 210 & 210 & - & 7 \\
\hline F8 & $4: 1$ & 560 & 140 & 210 & 140 & 3.5 & 7.0 \\
\hline F9 & $4: 1$ & 560 & 140 & 210 & 140 & 7 \\
\hline
\end{tabular}

\section{a. Preparation of Casting Solution}

The casting solutions were prepared by dissolving weighed quantities of polymers in acetone-methanol (1:1) mixture. The drug, plasticizer and permeation enhancer were then added to the polymer solution and thoroughly mixed to form a homogeneous mixture. The volume was made up to $7 \mathrm{ml}$ with solvent mixture. Entrapped air bubbles were removed by applying vacuum. Composition of formulation is given in Table 1 .

\section{b. Preparation of Transdermal Patches}

Casting solution $(5 \mathrm{ml})$ was poured into glass moulds and dried at room temperature for $24 \mathrm{hrs}$ for solvent evaporation. The patches were removed by peeling and cut into square dims of $4 \mathrm{~cm} \times 4 \mathrm{~cm}\left(16 \mathrm{~cm}^{2}\right)$. These patches were kept in desiccator for 2 days for further drying and wrapped in aluminium foil, packed in selfsealing covers ${ }^{7-9}$.

\section{Physico-mechanical characterization of transdermal patches}

\section{a. Physical appearance}

All the formulated transdermal patches were visually inspected for colour, flexibility, homogeneity and smoothness ${ }^{10}$.

\section{b. Thickness}

The thickness was measured at five different places on a single patch using a screw gauge. The average and standard deviation of five readings was calculated for each batch of the films ${ }^{10-12}$.

\section{c. Weight uniformity}

The films of different batches were dried at $60{ }^{\circ} \mathrm{C}$ for $4 \mathrm{~h}$ before testing. Five patches from each batch having diameter of $1 \mathrm{~cm}^{2}$ were weighed on a digital balance. The average weight and the standard deviation values were calculated from the individual weights ${ }^{12}$.

\section{d. Folding endurance}

Folding endurance was measured manually for the prepared films. A strip of film $\left(2 \times 2 \mathrm{~cm}^{2}\right)$ was cut evenly and repeatedly folded until it broke. The number of times the film could be folded at the same place without breaking was observed ${ }^{7,13}$.

\section{e. Tensile strength}

The tensile strength and percent elongation of the prepared films were performed using the method developed by Allen et $a l^{14}$. A simple apparatus designed at laboratory was used to carry out the measurement (Fig.1). A strip of $2.5 \times 5 \mathrm{~mm}$ was selected and attached to a clip on one end of a flat wooden surface. The thread was attached carrying a pan at the other end. The points of attachments were kept $0.5 \mathrm{~cm}$ from both the sides, so as to get even force distribution and to avoid breaking of film abruptly. The other end of thread carrying the pan was allowed to slide over a pulley opposite to fixed end. Weights were added in the pan in increasing order till the point of break-up. The elongation of the film at the point of break-up was also measured. The tensile strength was calculated as per Alien's formula; Tensile strength = (Break force/a $\mathrm{x} \mathrm{b}) \mathrm{X}(1+\Delta \mathrm{L} / \mathrm{L})$, where, $\mathrm{a}$ is the thickness, $\mathrm{B}$ is the width of the strip of film, $\Delta \mathrm{L}$ is the elongation at the breaking point and $\mathrm{L}$ is the length of the test strip (mm). 


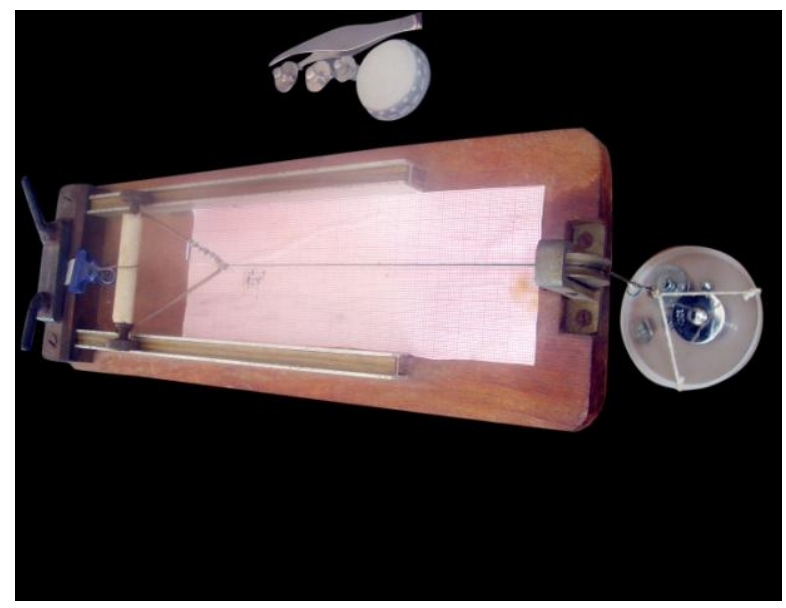

Figure 1: Instrument for the measurement of tensile strength of films

\section{f. Hardness}

The apparatus employed for hardness determination was designed in the laboratory using the literature report (Fig. 2 ). It consists of a wooden stand of $11 \mathrm{~cm}$ height and top area of $16 \mathrm{~cm} \times 16 \mathrm{~cm}$. A small pan was fixed horizontally to one end of the $2 \mathrm{~mm}$ thick iron rod whose other end is reduced to a sharp point. A hole of $0.2 \mathrm{~cm}$ was made at the center of top area of a wooden stand, which was supporting the pan rod. An electric circuit was made with two 1.5-volt battery and a three volt electric bulb in such a way that the bulb lights only when circuit is completed through the contact of a metal plate and sharp end of the rod. The film was placed between the metal plate and sharp end of the rod. The increments of weights were gradually added at an interval of 10 seconds o to the surface of wooden plate and when the hardness of the film exceeded, the sharp end penetrates across the film, contact the metal plate and the bulb glows. The average of five such readings was noted at different places of the film and the mean values for the hardness is recorded $^{14}$.

\section{g. Drug content uniformity}

The film of $1 \mathrm{~cm}^{2}$ area was cut into small pieces and transferred in to a graduated glass stoppered flask containing $15 \mathrm{ml}$ of methanol. The flask was shaken continuously for $24 \mathrm{hrs}$ in a mechanical shaker. Then the solution was filtered and residue was washed with methanol. The filtrate was made up to $100 \mathrm{ml}$ with phosphate buffer $\mathrm{pH} 7.4$ containing $40 \%$ v/v PEG 400 and the absorbance was measured at $358.5 \mathrm{~nm}$ in a double beam UV spectrophotometer (Systronics-2203) using the placebo film solution as blank and the drug content was determined $^{13}$.

\section{In-vitro Drug Release Studies}

In vitro drug release studies were performed by using Keshery - Chein diffusion cell with cellophane membrane. The receptor compartment was filled with 30 $\mathrm{ml}$ of phosphate buffer $\mathrm{pH} 7.4$ containing $40 \%$ v/v PEG 400 as diffusion media. The prepared transdermal film of

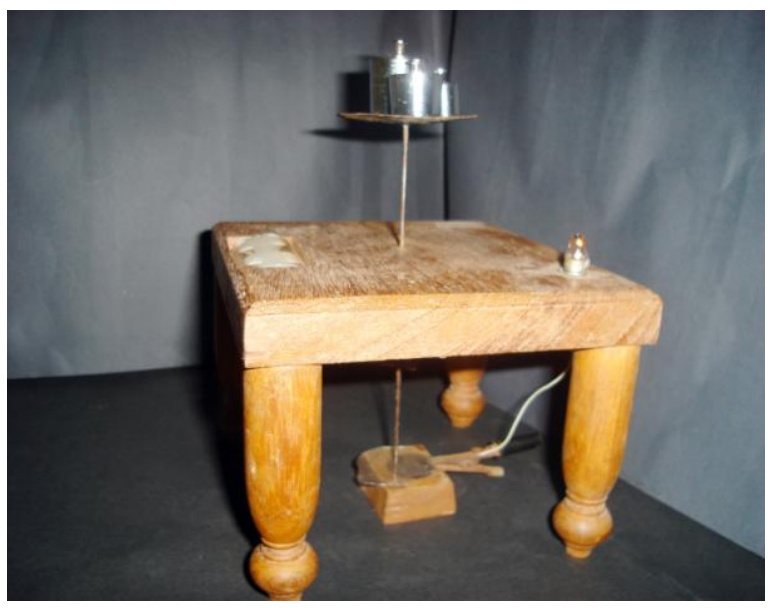

Figure 2: Instrument for the measurement of hardness of films
$1 \mathrm{~cm}^{2}$ was placed in the donor compartment. The whole assembly was fixed on a hot plate magnetic stirrer and the solution in the receptor compartment was continuously stirred at $100 \mathrm{rpm}$ using magnetic beads and the temperature was maintained at $37 \pm 1^{\circ} \mathrm{C} .3 \mathrm{ml}$ sample of the receptor fluid were withdrawn at predetermined time intervals and replaced immediately with same volume of fresh diffusion media. The samples were analyzed for drug content at $358.5 \mathrm{~nm}$ using UV - visible spectrophotometer (Systronics-2203) after suitable dilution with diffusion media ${ }^{18}$.

\section{Ex-vivo Skin Permeation Studies}

The healthy skin from the forearm region of cadaver brought for autopsy was taken in a sealed evacuated plastic bag in a thermos containing ice. The human skin was freed from fat by the use of Irish scissors till the dermis is seen. The hair was cut and then the skin was allowed to stand at room temperature and rehydrated by immersing in distilled water for 15 minutes. Then the cadaver skin was mounted between donor and receptor compartment of the diffusion cell with epidermis facing towards the donor compartment. $30 \mathrm{ml}$ of phosphate buffer $\mathrm{pH} 7.4$ containing $1 \% \mathrm{w} / \mathrm{v}$ sodium lauryl sulphate was used as elution medium. The films of $1 \mathrm{~cm}^{2}$ were placed in between the donor and the receptor compartment in such a way that the drug releasing surface faced toward the receptor compartment. The elution medium was magnetically stirred for uniform drug distribution at a speed of 100rpm. The temperature of the whole assembly was maintained at $37 \pm 1^{\circ} \mathrm{C}$ by thermostatic arrangements. An aliquot of $3 \mathrm{ml}$ was withdrawn at a suitable interval and an equivalent volume of fresh buffer was replaced. The amount of drug permeated across the membrane was determined at 358.5 $\mathrm{nm}$ spectrophotometrically after proper dilution with the elution medium. The cumulative amount of drug permeated was calculated and plotted against time ${ }^{18-20}$.

Estimation of area of patch required for desired release rate 
The mathematical description of drug release that follow zero order kinetics is based on the equation; $\mathrm{Kr}=$ $\mathrm{Ke} . \mathrm{Cd}$.Vd.BW where $\mathrm{Kr}$ is rate constant for drug release, $\mathrm{Ke}$ is the first order rate constant for drug elimination, $\mathrm{Cd}$ is the therapeutic drug concentration, $\mathrm{Vd}$ is the volume of distribution and BW is the standard body weight. For felodipine, $\mathrm{t}_{1 / 2}=12 \mathrm{~h}, \mathrm{Cd}=6.24 \mu \mathrm{g} / \mathrm{ml}$ and $\mathrm{Vd}=10 \mathrm{l}$ and therefore the desired drug release rate can be calculated as $\mathrm{Kr}=(0.693 / 12) \times 6.24 \times 10 \times 70=252.25 \mu \mathrm{g} / \mathrm{hr}$. Hence, area of patch $(\mathrm{A})$ required for desired release rate is $\mathrm{A}=$ $\mathrm{Kr} /(\mathrm{Kp} / \mathrm{S})$, where $\mathrm{Kr}$ is the required drug release rate $(\mathrm{mg} / \mathrm{h})$ and $\mathrm{S}$ is the surface area of the film subjected to diffusion $\left(\mathrm{cm}^{2}\right)^{21,22}$.

\section{Compatibility Studies}

The D.S.C. and I.R. studies were performed to check the compatibility of drug and polymers. Spectra of the pure FD, ERS, ERL and the formulated film (F9) were taken individually the peaks were compared for any significant deviation. $^{23,24}$.

\section{Stability Study}

The stability studies of the formulated transdermal patches were carried out on selected films (F9) as per ICH guidelines. The patches were wrapped in aluminium foil and stored at $40 \pm 0.5^{\circ} \mathrm{C}$ and $75 \pm 5 \% \mathrm{RH}$ for 3 months. The sample patches were withdrawn at $0,30,60$ and 90 days and analysed for the drug content and drug releasing charecteristics ${ }^{24,25}$.

\section{Primary Skin Irritancy Studies}

Patches were applied to the shaved skin on one side of the back of rabbit and secured using adhesive tape. On other back side of the rabbit, control patch (without drug) was secured in a similar way. The animal was observed for any sign of erythema or oedema for a period of 48 hours

\section{Lamination of Transdermal Patch}

In view of the limited usefulness of the film (Fig. 3) to the patient, an attempt has been made to develop the complete transdermal therapeutic system of the drug by using backing membrane and release liner (Fig. 4). The transdermal patch of $1 \mathrm{~cm}$ diameter was cut and placed on an aluminium foil of $1.3 \mathrm{~cm}$ diameter that serves as the backing membrane. A solution of polyisobutylene was applied along the circumference of the aluminium foil and dried at room temperature for $10 \mathrm{hrs}$. The patch was covered with silicone coated release liner ${ }^{18}$.

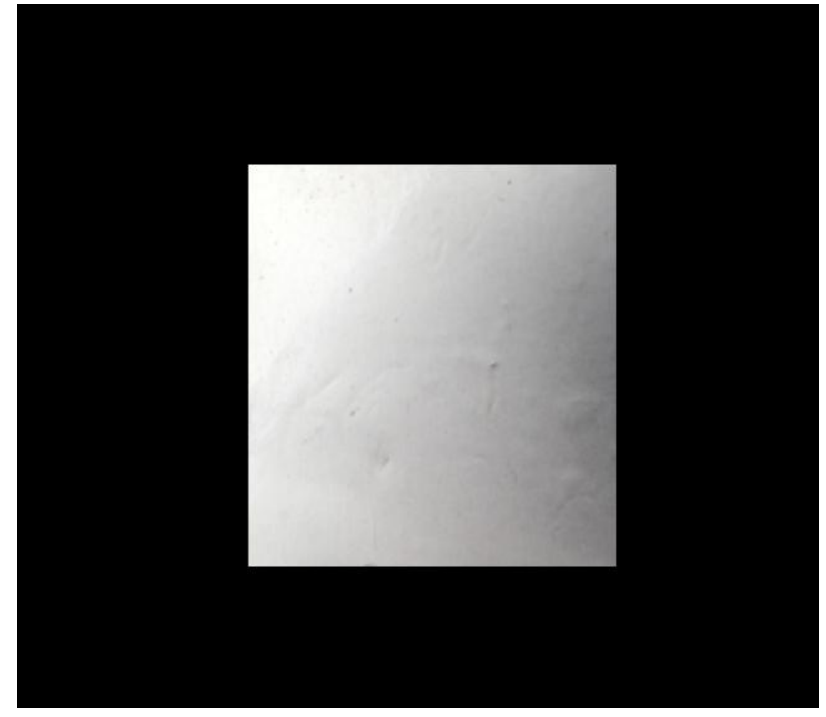

Figure 3: Prepared transdermal film

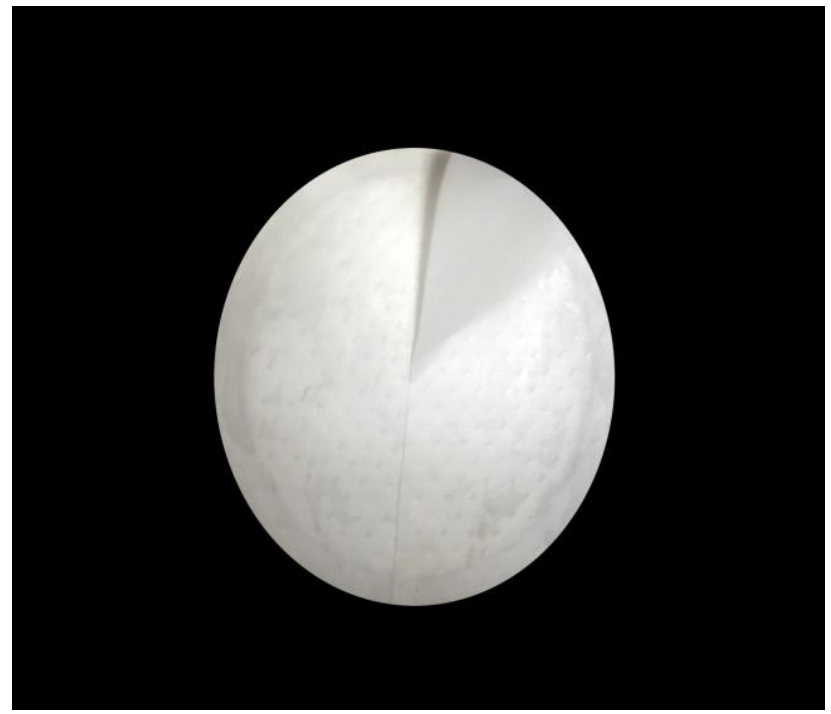

Figure 4: Laminated transdermal patch

\section{RESULTS AND DISCUSSION}

\section{Physico-mechanical characterization}

In the present study, total nine patches were formulated by varying polymer (ERS / ERL) ratio, plasticizer and permeation enhancer concentration. In all these formulations a constant amount of drug $(210 \mathrm{mg})$ was maintained. $5 \mathrm{ml}$ of the casting solution was spread in to $25 \mathrm{~cm}^{2}$ so that each $\mathrm{cm}^{2}$ contains approximately $6.0 \mathrm{mg}$ of

the drug. The prepared films were slightly pale yellow coloured with homogeneous appearance and possessed uniform surface. Drug was uniformly distributed through the matrix film. There were no observable particles of drug in the matrix film. The physicomechanical valuation data of the films was presented in Table 2. 
Table 2: Physico-mechanical characters of formulated transdermal film

\begin{tabular}{|c|c|c|c|c|c|c|}
\hline $\begin{array}{c}\text { Formulation } \\
\text { Code }\end{array}$ & $\begin{array}{c}\text { Thickness } \\
(\mathbf{m m})\end{array}$ & Weight $\mathbf{( m g )}$ & $\begin{array}{c}\text { Folding } \\
\text { Endurance }\end{array}$ & $\begin{array}{c}\text { \% Elongation } \\
\text { at break }\end{array}$ & $\begin{array}{c}\text { Tensile strength } \\
\left(\mathbf{K g} / \mathbf{c m}^{2}\right)\end{array}$ & $\begin{array}{c}\text { Hardness } \\
(\mathbf{K g})\end{array}$ \\
\hline F1 & $0.209 \pm 0.020$ & $18.647 \pm 0.154$ & $78 \pm 1.93$ & $6.8 \pm 1.541$ & $0.349 \pm 0.066$ & $0.438 \pm 0.047$ \\
\hline F2 & $0.213 \pm 0.025$ & $19.232 \pm 0.208$ & $94 \pm 1.51$ & $8.2 \pm 1.164$ & $0.362 \pm 0.073$ & $0.423 \pm 0.032$ \\
\hline F3 & $0.206 \pm 0.031$ & $19.784 \pm 0.177$ & $112 \pm 2.05$ & $8.7 \pm 1.275$ & $0.375 \pm 0.051$ & $0.396 \pm 0.065$ \\
\hline F4 & $0.214 \pm 0.022$ & $20.323 \pm 0.251$ & $119 \pm 2.48$ & $9.5 \pm 1.845$ & $0.389 \pm 0.012$ & $0.387 \pm 0.071$ \\
\hline F5 & $0.226 \pm 0.012$ & $22.492 \pm 0.208$ & $167 \pm 1.44$ & $17.4 \pm 2.075$ & $0.422 \pm 0.070$ & $0.384 \pm 0.019$ \\
\hline F6 & $0.235 \pm 0.016$ & $23.647 \pm 0.152$ & $192 \pm 2.35$ & $21.5 \pm 2.204$ & $0.476 \pm 0.045$ & $0.373 \pm 0.026$ \\
\hline F7 & $0.242 \pm 0.022$ & $24.995 \pm 0.284$ & $214 \pm 3.67$ & $27.1 \pm 2.516$ & $0.565 \pm 0.098$ & $0.352 \pm 0.035$ \\
\hline F8 & $0.243 \pm 0.012$ & $23.931 \pm 0.173$ & $196 \pm 1.92$ & $22.4 \pm 2.081$ & $0.499 \pm 0.036$ & $0.376 \pm 0.029$ \\
\hline F9 & $0.245 \pm 0.010$ & $24.267 \pm 0.157$ & $204 \pm 2.07$ & $23.9 \pm 1.947$ & $0.527 \pm 0.053$ & $0.375 \pm 0.057$ \\
\hline
\end{tabular}

The folding endurance was measured manually and it is found that ERL / ERS films without adjuvants were hard, brittle and fragile with low folding endurance. To prevent embrittlement, a plasticizer, DBP was tried at various concentrations: $10 \% \mathrm{w} / \mathrm{w}, 20 \% \mathrm{w} / \mathrm{w}$ and $30 \% \mathrm{w} / \mathrm{w}$ in respect to the dry weight of the polymer. The plasticizer can diffuse in to and softens the polymer matrix. Folding endurance value were $78 \pm 1.93$ for formulation $\mathrm{F} 1$ and $204 \pm 2.07$ for formulation F9, other formulations were within these ranges, which shown that hydrophilic polymer (ERL) and the presence of plasticizer can provide higher folding endurance and good flexibility. The results suggested that the patches would not break and would maintain their integrity with general skin folding when applied. However, the film with $30 \% \mathrm{w} / \mathrm{w}$ of DBP was not satisfactory because of its sticky nature.

The films were evaluated for the film thickness at various points. It was found that the thickness at the edges of the rectangular tray was a bit higher and uneven compared to the rest of the parts of the film. It may be due to the curvature of the viscous slurry at the edges of the foil due to surface tension. After removing these edges, films were remeasured for thickness and it was observed to have uniform thickness and low standard deviation. It indicates the uniformity of the films prepared by the solvent casting method. The thickness was found to be high with films prepared with DBP as plasticizer. As the proportion of DBP was increased, the thickness was also increased (Table 2). No significant difference in the average weight among each group indicating that the patches are uniform throughout. However the average weight of the patches was slightly increased with hydrophilic polymer ERL. The increase in the weight may be due to the hydrophilic nature of the adjuvants which may absorb moisture from the atmosphere resulting in increase in weight. It was also found that, with the incorporation of hydrophilic polymer, ERL and plasticizer, DBP, were increased the tensile strength and the percentage elongation where as the hardness of the film decreased, but, the incorporation of $\mathrm{OA}$ as permeation enhancer at $2.5 \% \mathrm{w} / \mathrm{w}$ and $5 \% \mathrm{w} / \mathrm{w}$ did not affect significantly the physicomechanical and handling properties of the film.

Good uniformity of the drug content among the patches was observed for all the formulations which ranged from $94.75 \%$ to $98.42 \%$ (Table 3). Based on the initial drug loading, all the formulations were containing above 5.628 $\pm 0.0387 \mathrm{mg}$, which proves that the process employed to prepare the films in this study was capable of producing films with uniform drug content and minimum batch variability.

\section{In-vitro drug release studies}

In-vitro drug release studies from transdermal patches were carried out through cellophane membrane and the results are summarized in Figures 5 and 6 . It was observed that, as the concentration of ERL increased, the percentage of drug release also increased. More permeability of these films may be due to its hydrophilic nature, which increases the porosity and diffusivity of the film and thermodynamic activity of the drug. The release pattern of FDP was found to be enhanced significantly when DBP was incorporated to the films as plasticizer, It is indicated that the drug release rate increased gradually as the amount of DBP was increased. The results suggest that ERL and DBP had major influence on drug release.

Table 3: Drug content of prepared transdermal films

\begin{tabular}{|c|c|c|}
\hline Formulation Code & $\begin{array}{c}\text { Amount of drug }\left(\mathbf{1 c m}^{\mathbf{2}} \mathbf{)} \mathbf{( m g )}\right. \\
\mathbf{A M} \pm \mathbf{S D}\end{array}$ & $\begin{array}{c}\text { Percentage of drug }\left(\mathbf{1 c m}^{\mathbf{2}}\right) \\
\text { AM } \pm \text { SD }\end{array}$ \\
\hline F1 & $5.716 \pm 0.0349$ & $95.278 \pm 0.5704$ \\
\hline F2 & $5.749 \pm 0.0343$ & $95.827 \pm 0.5679$ \\
\hline F3 & $5.837 \pm 0.0338$ & $97.283 \pm 0.5678$ \\
\hline F4 & $5.734 \pm 0.2667$ & $95.556 \pm 0.4556$ \\
\hline F5 & $5.851 \pm 0.0515$ & $97.517 \pm 0.8585$ \\
\hline F6 & $5.773 \pm 0.0536$ & $96.222 \pm 0.9298$ \\
\hline F8 & $5.640 \pm 0.0217$ & $93.955 \pm 0.3534$ \\
\hline F9 & $5.691 \pm 0.0381$ & $94.844 \pm 0.6609$ \\
\hline & $5.628 \pm 0.0387$ & $93.800 \pm 0.6435$ \\
\hline
\end{tabular}




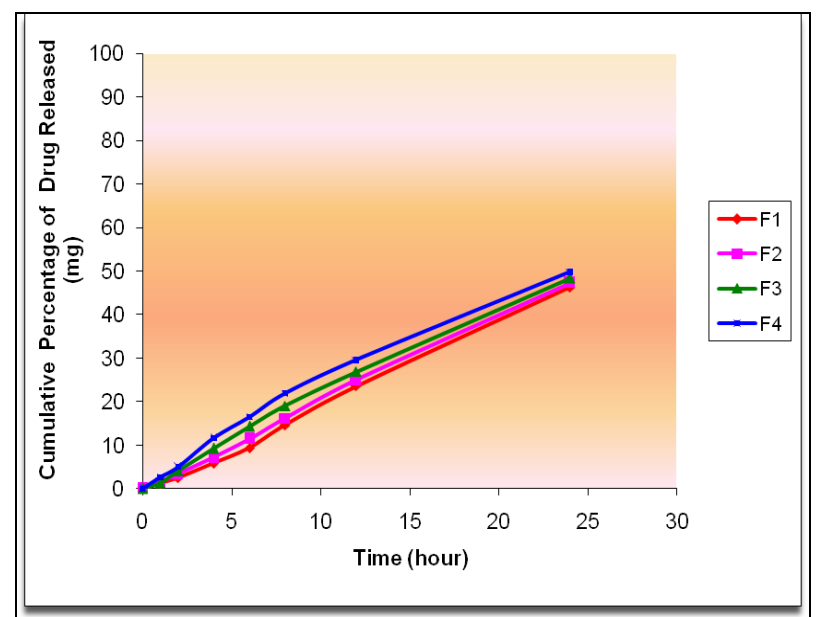

Figure 5: Effect of polymer composition (ERL/ERS) on the in-vitro drug release of formulated transdermal films(F1 to F4)

The rate and mechanism of release of felodipine were analysed by fitting the drug release data in to zero order equation, first order equation, Higuchi and KorsemayerPeppas models. The cumulative amount of drug released from the patches, when plotted against square root of

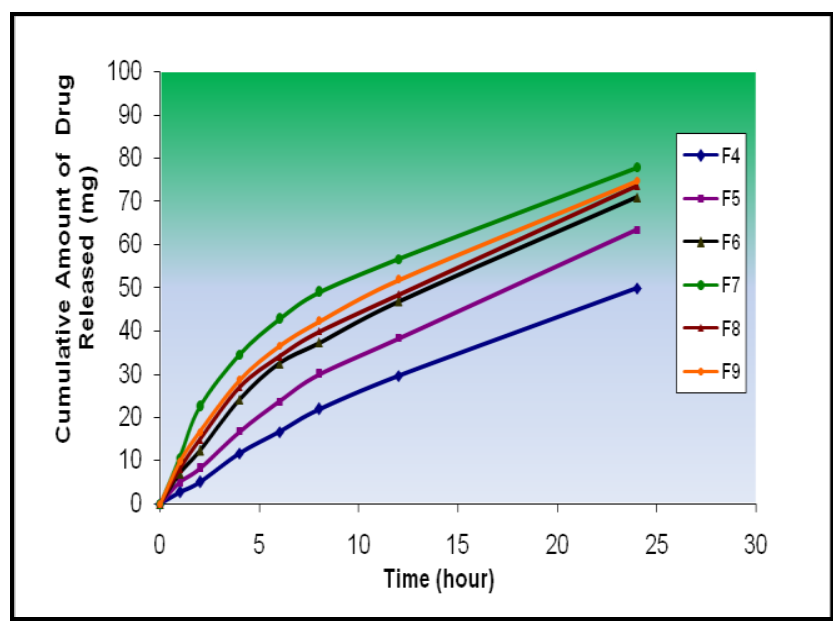

Figure 6: Effect of the concentration of plasticizer (DBP) and permeation enhancer (OA) on the in-vitro drug release (F4 to $\mathrm{F} 9)$

time, the release profiles of drug seemed to follow Higuchi model as it was evidenced by correlation coefficients $\left(r^{2}=0.97\right.$ to 0.99$)$ better than zero order $\left(r^{2}\right.$ $=0.95$ to 0.97$)$ and first order $\left(r^{2}=0.53\right.$ to 0.56$)$ (Fig.7).

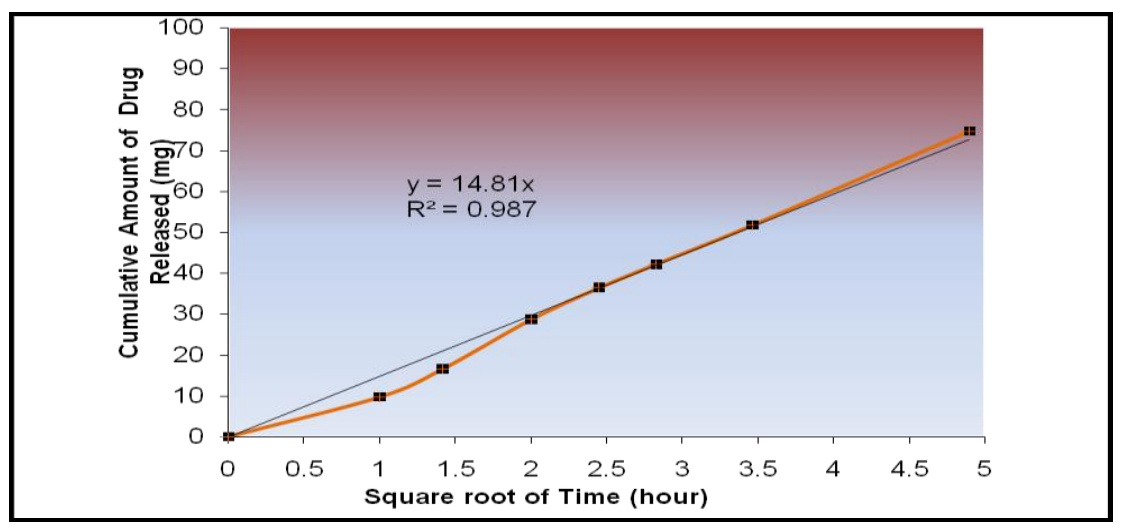

Figure 7: Higuchi model release of felodipine from transdermal film-F9

To define the mechanism of drug release from the transdermal patches, the data was further analyzed by the following empirical equation, $\mathrm{Mt} / \mathrm{M} \alpha=\mathrm{K} \mathrm{t}^{\mathrm{n}}$, where $\mathrm{Mt} / \mathrm{M} \alpha$ is the fraction of drug released at time $\mathrm{t}, \mathrm{K}$ is the kinetic constant, and $\mathrm{n}$ is the diffusional release exponent characterizes the mechanism of drug release. The diffusion exponent has a value of 0.587- 0.753, which indicated that the drug release was by non-fickian model.

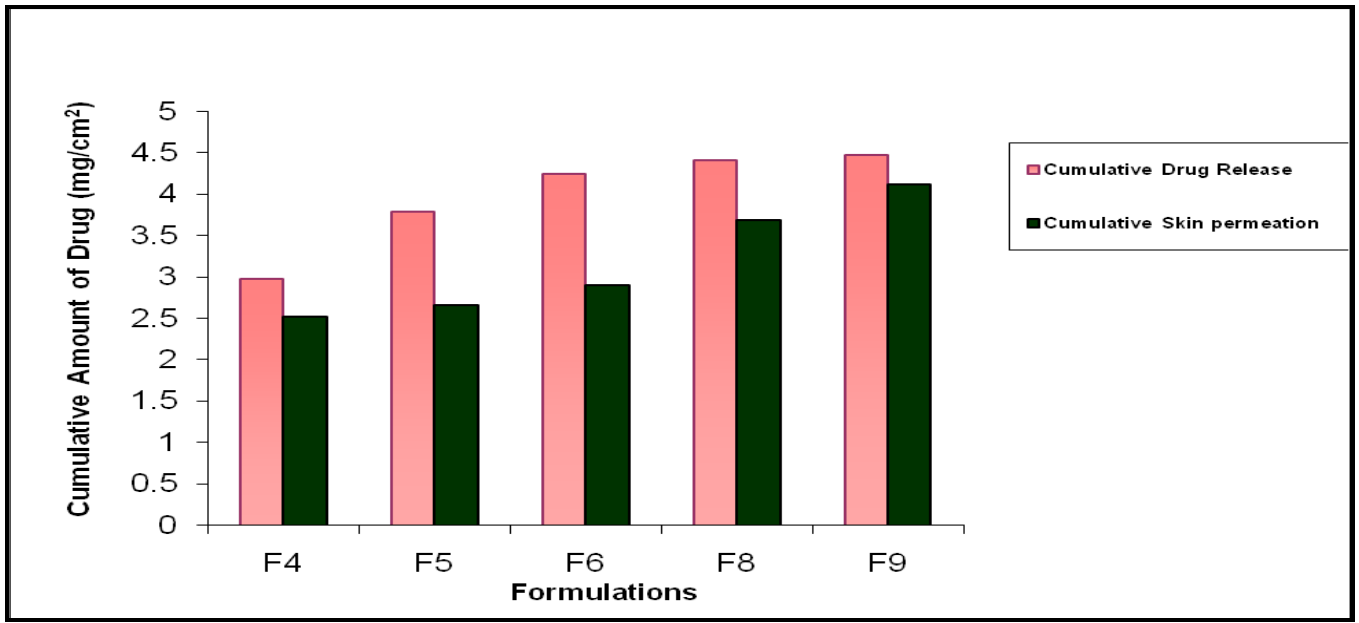

Figure 8: Comparison of in-vitro release and ex-vivo skin permeation of felodipine from transdermal film-F9 


\section{Ex-vivo drug permeation studies}

The ex-vivo permeation of the drug through human cadaver skin was slightly lesser than cellophane membrane. However, the incorporation of OA can significantly improve the drug permeation characteristics through human cadaver skin. (Fig.10). Incorporation of

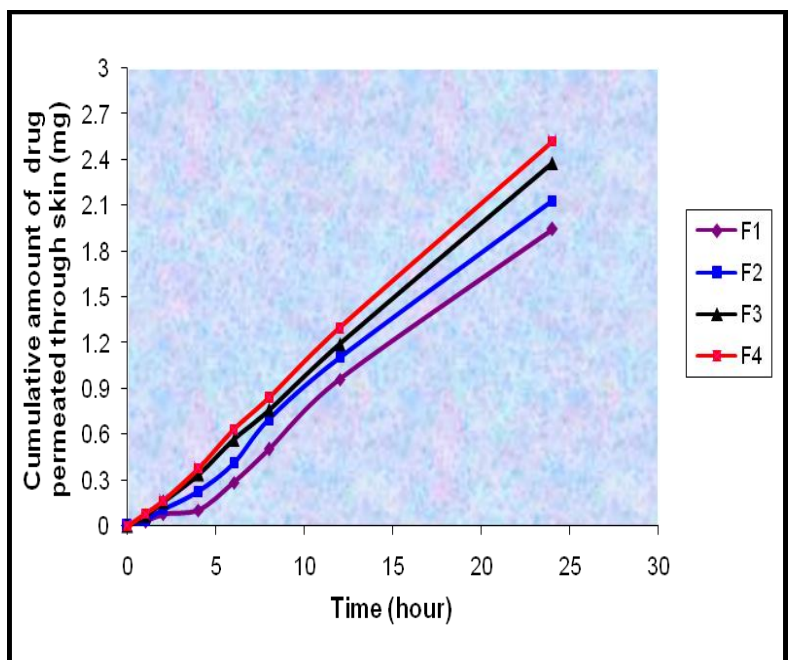

Figure 9: Effect of polymer composition (ERL/ERS) on the ex-vivo skin permeation of drug from transdermal films (F1 to F4)

The in vitro drug release and ex vivo skin permeation studies revealed that the combined use of plasticizer and permeation enhancers increased the release rate and amount of the drug from the patches compared to that of their single use. The incorporation of DBP in to the FDeudragit films may be useful for improving the physicomechanical and drug release properties of the films and the incorporation of OA into the films may be useful for attaining required drug permeation. Thus, the film-F9 with ERL: ERS ratio 1:4, 2\% w/w OA as permeation enhancer and $20 \% \mathrm{w} / \mathrm{w}$ DBP as plasticizer showed the best results which exhibited the cumulative percentage of drug release of $75.73 \pm 2.179 \%$ and the cumulative amount of drug permeation across skin of $4321 \pm 11.533$ $\mu \mathrm{g} / \mathrm{cm}^{2}$ in $24 \mathrm{hrs}$. The transdermal flux, permeability coefficient and area of the film required for desired release rate for the transdermal film-F9 were calculated and are reported in Table 4.

Table 4: Transdermal flux, permeability coefficient and area of the film required for desired release rate for the transdermal film-F9

\begin{tabular}{|l|l|}
\hline Parameters & F9 Film \\
\hline Cumulative \% of drug released-24 hr & $75.73 \%$ \\
\hline $\begin{array}{l}\text { Cumulative amount of drug } \\
\text { permeated through skin - 24 hr }\end{array}$ & $4321.2 \mu \mathrm{g} / \mathrm{cm}^{2}$ \\
\hline Lag time & $0.8 \mathrm{hr}$ \\
\hline Transdermal flux & $187.97 \mu \mathrm{g} / \mathrm{hr} / \mathrm{cm}^{2}$ \\
\hline Permeability coefficient & $3.13 \times 10^{-2} \mathrm{~cm}^{2} / \mathrm{hr}$ \\
\hline Targeted flux & $729 \mu \mathrm{g} / \mathrm{hr}$ \\
\hline Area of film required for TDDS & $3.878 \mathrm{~cm}$ \\
\hline
\end{tabular}

Figure 10: Effect of the concentration of plasticizer (DBP) and permeation enhancer (OA) on the ex-vivo skin permeation of drug from transdermal film (F4 to F9)

\section{Compatibility studies}

The D.S.C. and I. R. studies revealed that there was no significant change in the original peak of the drug and the polymers after formulating the patch, indicating that there is no interaction between drug and polymers.

\section{Stability study}

Stability studies were carried out for 6 months and the films was observed for various physico-mechanical and drug release characteristics. It was found that, there is no significant change in physical appearance, thickness, weight, folding endurance and tensile strength and drug content. Drug release and permeation characteristics did not alter significantly even after 6 months storage.

\section{Primary skin irritancy studies}

Results of skin irritancy study revealed that neither blank patch nor patch containing FD cause any noticeable sign of erythema or oedema on rabbit skin throughout the period of $48 \mathrm{hrs}$, indicating the skin compatibility of blank patch as well as patch containing drug.

\section{CONCLUSION}

Based on the physico-mechanical and drug release characteristics, ERS 100/RL 100 (1:4) films with DBP $(20 \% \mathrm{w} / \mathrm{w})$ and OA $(2 \% \mathrm{w} / \mathrm{w})$ are suitable to design matrix dispersion type transdermal films for FDP.. The fabricated transdermal delivery system containing FDP is one of the best controlled drug delivery systems in the effective therapy and prophylaxis of hypertension, angina pectoris and cardiac arrhythmia, where the drug is made available for an extended period of time, so frequency of

\footnotetext{
2011, JDDT. All Rights Reserved
} 
administration can be minimized. The film composition and additives can be optimized to get the release over prolonged period of time as once a week or once a month transdermal formulations. Further, these findings may help the industry to scale up for commercial production.

\section{ACKNOWLEDGEMENT}

The authors are thankful to Cipla Ltd., Mumbai for sparing gift sample of felodipine for the research work and to the management of Malik Deenar College of Pharmacy, Kasaragod and N.G.S.M Institute of Pharmaceutical Sciences, Mangalore for providing the necessary laboratory facilities and constant encouragement.

\section{REFERENCES}

1. Misra AN. Transdermal drug delivery in: Jain N.K.(Ed). Controlled and novel drug delivery. Varghese Publication, New Delhi; 2004:101-127.

2. Nayak SH, Nakhat PD, Yeole PG, Transdermal drug delivery system, The Indian Pharmacist, Sept. 2004:7-14.

3. Jamakandi VG, Ghosh B, Desai BG, Khanam J, Recent trends in transdermal cardiovascular therapy, Indian J. Pharm. Sci., Sept-Oct. 2006:556-561.

4. Oates JA, Nancy JB. Antihypertensive agents and the drug therapy of hypertension. Goodman and Gilman's the pharmacological therapeutics.10th ed. Mc.Graw Hill Medical Publishing Division: 871-896.

5. Tripathi KD. Essentials of medical pharmacology. 5th ed. Jaypee Brothers. New Delhi; 1999:504-505.

6. Parfitt K. Martindale: the complete drug reference. 3rd edition, Royal Pharmaceutical Society, London; 2002:920.

7. Sankar V, Johnson DB, Sivanad V, Ravichadran V, Raghuram S, Design and evaluation of nifedipine transdermal patches, Indian J. Pharm. Sci., 2003; 65(5):510515 .

8. Mohammed A, Yasmin S, Asgar A, Matrix type transdermal drug delivery systems of metoprolol tartarate, Acta Pharm., 2003; 53:119-125.

9. Wagh MP, Dalvi H, Bagal M, Formulation and evaluation of transdermal drug delivery system for simvastatin. Indian drugs, 2009; 46 (3):221-5.

10. Kulkarni R, Doddayya H, Marihal SC, Patil CC, Habbu PV, Comparative evaluation of polymeric films for transdermal application, The Eastern Pharmacist, 2000; 43(516):109112.

11. Anil SJ, Kevin GC, Harinath MN, Formulation and evaluation of transdermal patches of metoprolol tartarate, The Indian Pharmacist, June. 2009:69-74.

12. Kusum D, Paranjothy KL, Development and evaluation of free films and transdermal patches of ketorolac trimethamine using polymers and pressure sensitive adhesives, The Eastern Pharmacist, 1998; 42(485):97-100.

13. Udupa $\mathrm{N}$ et al., Design and evaluation of captopril transdermal preparations, Indian Drugs, 1992; 29(15):680685 .
14. Seth AK, Agarwal GP, Saini TR, Evaluation of free films, Indian Drugs, 1985; 23:45-7.

15. Nakamura F, Ohta R, Machida $\mathrm{Y}$, Nagai $\mathrm{T}$, In vitro and in vivo nasal mucoadhession of some water soluble polymers, Int. J.Pharm. 1991; 174-81.

16. Hanan EN et al., Effect of various penetration enhancers concentrations on diclofenac sodium release from cellulose acetate phthalate polymeric film, Asian J. Pharm. Sci., JanMarch 2011; 33-40.

17. Pao-chu $\mathrm{Wu}$ et al., in vitro percutaneous absorption of captopril through excised rabbit skin, Int. J. Pharm., 1996; 143:119-123.

18. Saqib Z, Aquil M, Ali A, Ahmad S, Transdermal drug delivery of labetolol hydrochloride: system development, in vitro, ex vivo and in vivo characterization, Current Drug Delivery, 2005; 2:125-131.

19. Mourya VK, Saini TR, Studies on skin permeation of piroxicam, Indian Drugs, 1997; 34(11):656-657.

20. Narasimha Murthy S et al., Drug release from terbutalin sulphate transdermal films across human cadaver skin, Indian J. Pharm. Sci., 1997; 59(2):75-76.

21. Murty TEGK, Kishore VS, Effect of casting solvent and polymer on permeability of propanalol hydrochloride through membrane controlled transdermal delivery system, Indian J. Pharm. Sci., 2007; 69(5):646-650.

22. Mamatha T, Venkateshwara Rao J, Mukkanti K, Ramesh G, Development of matrix type transdermal patches of lercanidipine hydrochloride: physicochemical and in-vitro characterization, DARU, 18 (1): 9-16.

23. Das MK, Bhattacharya A, Ghosal SK, Transdermal delivery of trazodone hydrochloride from acrylic films prepared from aqueous latex, Indian J. Pharm. Sci., 2006; 68(1):41-46.

24. Mandal SC, Mandal M, Ghosal SK, Compatibility and stability studies of matrix type transdermal drug delivery systems. Indian Drugs, 1996; 33(10):511-513.

25. Shingade GM, Aamer Quazi, Sabale PM, Grampurohit ND, Gadhave MV, Review on recent trend on transdermal delivery system, J. Drug Delivery and Therapeutics, 2012; 2(1):66-75. 